\title{
Prevalence of asthma among male 16 to 18-year-old adolescents in the Northern Borders Region of Saudi Arabia
}

\author{
Mohammed Farhan Alruwaili ${ }^{1}$, Amal Elwan ${ }^{2}$
}

${ }^{1}$ M.B.B.S, Resident in Saudi Board of Family Medicine, Joint Program of Saudi Board of Family Medicine, Arar City, Northern Borders Region, Saudi Arabia

${ }^{2}$ Consultant of Public Health, Saudi Board of Family Medicine, Northern Borders, Arar City, Saudi Arabia

\section{Type of article: Original}

\begin{abstract}
Background: Asthma is a common chronic disease in adolescents, and has led to a significant morbidity and disability. Few studies have estimated the prevalence of asthma in the Northern Borders Region of Saudi Arabia. Only limited data has been available about prevalence of asthma in adolescents' age.

Objectives: The objectives of this study were to assess the prevalence of asthma and associated symptoms in 16 to 18-year-old adolescents, and to assess the level of asthma control among students with physician-diagnosed asthma, in the Northern Borders Region of Saudi Arabia.

Methods: A cross-sectional study was carried out on 511 male 16 to 18 -year-old students in the Northern Borders Region of Saudi Arabia during the academic year 2017-2018. An International Study of Asthma and Allergies in Children (ISAAC) questionnaire and Asthma Control Test (ACT) were used as the measurement tool. The data were analyzed by SPSS version 20, using descriptive statistics and Chi-square test. A p-value of 0.05 or less was considered, statistically significant.

Results: Among the 511 students, the prevalence of physician-diagnosed asthma was $11.4 \%$. The prevalence of lifetime wheeze, and exercise-induced wheeze were $30.3 \%$ and $19 \%$ respectively. The prevalence of night cough and wheezing attack in the past 12 months were $17 \%$ and $16.8 \%$ respectively. A total of $51.8 \%$ of asthmatic students have poor asthma control.

Conclusions: The prevalence of asthma and associated symptoms in 16 to18-year-old students is high in the Northern Borders Region. Uncontrolled asthma was observed in half of asthmatic students.

Keywords: Asthma, Prevalence, Saudi Arabia, Control
\end{abstract}

\section{Introduction \\ 1.1. Background and study logic}

Asthma is a chronic airways disorder characterized by recurrent attacks of chest tightness, wheezing, cough and breathlessness (1). Symptoms of asthma vary in severity and frequency, and are related to one or more of airflow obstruction, bronchial hyper-responsiveness and underlying inflammation (1). Adolescents with asthma are at risk of significant morbidity and disability that affect their general health and will being (2). The severity variation of asthma can lead to different degrees of disability on emotional aspects, school attendance, social and physical activities of adolescents (3). Furthermore, adolescents with the lowest physical activity caused by asthma may have a higher risk of asthma attacks (4). Asthma prevalence has been increasing worldwide over the past decades (5), and it was $14.1 \%$ in the adolescent age group, globally (6). Recent figures show that 235 million people suffer from asthma in all countries, independently to the level of income. Undiagnosed and untreated asthma have a major impact on quality of life of the affected person as well as the families (7). Compared to other chronic obstructive

\section{Corresponding author:}

Dr. Mohammed Farhan Alruwaili, Al-Nasria, Ibn Majah Street, Arar City, Northern Borders Region, Saudi Arabia. Tel.: +966.550190115, Email: dr-pulse@hotmail.com

Received: May 08, 2018, Accepted: May 17, 2018, Published: June 2018

iThenticate screening: May 15, 2018, English editing: June 02, 2018, Quality control: June 02, 2018

This article has been reviewed / commented by three experts

Ethics approval: H-09-A-51

(C) 2018 The Authors. This is an open access article under the terms of the Creative Commons Attribution-NonCommercialNoDerivs License, which permits use and distribution in any medium, provided the original work is properly cited, the use is non-commercial and no modifications or adaptations are made. 
pulmonary disease like (COPD), asthma does not result in death, but left untreated and incompliance to treatment can be fatal, and the WHO estimate that380,000 persons died due to asthma in 2015 (7). In the Middle East, the prevalence of asthma is higher among younger boys and it is present in $7.57 \%$ of children aged 13-14 years (8). Few studies have assessed the prevalence of asthma in the Kingdom of Saudi Arabia. Prevalence of asthma in adults is unknown according to the Saudi Initiative for Asthma (2016), but it has reached up to 25\% in children (1). Prevalence of asthma has increased in Saudi Arabia from 8\% in 1986 to 23\% in 1995 among the ages between 6 and 18 years; and more than 2 million Saudis are affected (9). In Riyadh city (capital of Saudi Arabia), the prevalence of asthma was between $4.5 \%$ and $19.6 \%$ in students aged 16 to $18(10,11)$. In the south of Saudi Arabia, the prevalence of asthma was $27.5 \%$ at aged $7-19$ years (12), while it was $6.45 \%$ in the Northern Borders Region of Saudi Arabia among adults $\geq 15$ years according to the national household survey in 2013 (13). In other regions of Saudi Arabia such as Madinah city, Abha city and Taif area, asthma prevalence among school-age children was $23.6 \%, 9 \%$ and $13.1 \%$, respectively (14-16). Among both the developed and developing world, asthma has a high cost burden (17). In developed countries, 1-2\% of total healthcare costs is spent on asthma (18). Asthma represents $1.12 \%$ of total DALYs in Saudi Arabia (19), and is ranked at $26^{\text {th }}$ position in causes of death (20). The goals of this study are to estimate the prevalence of asthma and associated symptoms in 16 to 18 -year-old adolescents, and to assess the level of asthma control among asthmatic students in the Northern Borders Region of Saudi Arabia.

\subsection{Objectives}

The specific objectives of this study were: (1) To assess prevalence of asthma among adolescent male students at secondary schools in the Northern Borders Region of Saudi Arabia, (2) To assess control of asthma in the students with reported physician-diagnosed asthma.

\section{Material and Methods}

\subsection{Study design and time period}

A cross-sectional study was carried out on male 16 to18-year-old students in the Northern Borders Region of Saudi Arabia during the academic year 2017-2018. Arar city is the capital of the Northern Borders Region of Saudi Arabia with an estimated population of $311,473,88 \%$ of whom are Saudi citizens and Muslims. The Northern Borders Region represents $1.2 \%$ of the total population of the Kingdom of Saudi Arabia and has a desert climate (21).

\subsection{Participants}

\subsubsection{Selection criteria}

Inclusion criteria: male gender, adolescent age, resident in Arar city, Saudi, non-Saudi, and regular students. Exclusion criteria: Students who have hearing limitations or limited intellectual capabilities.

\subsubsection{Study population}

There are 21 secondary schools for boys in Arar city, Northern Borders Region of Saudi Arabia (22). The total number of regular secondary school male students in Arar city during the 2017-2018 academic years was 5,780 boys (22). Four of the 21 secondary schools were randomly selected with a total of approximately 540 male 16 to 18 -yearold students.

\subsection{Sampling}

2.3.1. Sample size

We used this valid formula to determine the sample size for cross sectional study (23): $\mathrm{n}=\mathrm{Z}^{2} \mathrm{p}(1-\mathrm{p}) / \mathrm{d}^{2}$

Where: $\mathrm{n}=$ sample size, $\mathrm{p}=$ percentage, picking a choice was $19.6 \%(11),=1.96$ for confidence level $95 \%$, and $\mathrm{d}=0.05$ for confidence interval and acceptable margin error of 5\% (23). Depending on this formula, the sample size was 243 and it was duplicated by cluster design effect to 486 students and increased 10\% for non-response, so the total number was 535 students.

\subsubsection{Sampling method}

Multi-stage random sample. First stage was a simple random sample, we randomly selected 4 boys' schools out of 21 schools. In the second stage, all students in selected schools were taken as a cluster.

\subsection{Measures and instruments}

The students completed the self-administered questionnaires in the classroom under supervision of the researcher. The first section included the socio-demographic questions (age, residence, nationality, etc.). The other instruments are presented as follows: 


\subsubsection{The International Study of Asthma and Allergy in Childhood (ISAAC)}

The ISAAC questionnaire was used to assess the prevalence of asthma. This is a self-administered questionnaire used to determine the prevalence of asthma among adolescents aged 13-14 years and its sensitivity and specificity were $85 \%$ and $81 \%$ respectively $(24,25)$. The ISAAC questionnaire was translated to Arabic language by three bilingual family medicine consultants and was translated back into English by an independent translator. The final translation was assessed and accepted by a panel of experts. The reliability of the translated questionnaire was 0.82 after a pilot study. This questionnaire covers the following variables: lifetime wheeze (if wheezing had ever occurred), current wheeze (in the past 12 months), number of wheezing attacks in the past 12 months, sleep disturbances due to wheeze, speech-limiting wheeze, physician-diagnosed asthma (if asthma had ever been diagnosed by a physician), exercise-induced wheeze, and night coughing in the past 12 months (24).

\subsubsection{Asthma control test (ACT)}

The ACT was used to assess the control of asthma. The ACT is a recommended and validated tool to assess asthma control by the guideline of the Saudi Initiative for Asthma (1). We used the Arabic version of ACT which is a valid tool for Arabic-speaking patients to assess asthma control with reliability of 0.92 (26). "The score of ACT is the sum of the five questions where each is scored from 1 (worst) to 5 (best) and the level of asthma control is categorized into: Controlled: An ACT score of $\geq 20$, Partially controlled: An ACT score of 16-19 and Uncontrolled: An ACT score of $<16 "$ (1).

\subsection{Data analysis}

The data were analyzed by IBMC SPSS $\odot$ Statistics version 20 (IBM@ Corp., Armonk, NY, USA), using descriptive statistics and Chi-square test. A p-value of 0.05 or less was considered significant.

\subsection{Ethical consideration}

Official permission was received from the Ministry of Education. Approval for this study was obtained from the research and ethics committee at Health Affairs General Directorate, Northern Borders Region of Saudi Arabia (Reg. \# H-09-A-51) with approval number: 3915. Verbal informed consent was taken from the students and the purpose of the study was explained to them. Students were assured that the surveys would be anonymous and that the data would be kept confidential during handling and storage.

\section{Results}

A total of 540 male students received the self-administered questionnaire. Of these, 29 questionnaires were excluded because of missing data. The concluded sample size was 511 with overall $94.6 \%$ response rate. The age of studied group was 17.08 years $( \pm 1.1), 454(88.9)$ were Saudi and $57(11.1 \%)$ were non-Saudi people. The current study estimated that, the prevalence of asthma was $11.4 \%$. The prevalence of lifetime wheeze, and exercise-induced wheeze was $30.3 \%$ and $19 \%$ respectively. The prevalence of night cough in the past 12 months and wheezing attack in the past 12 months was $17 \%$ and 16.8 respectively (Table 1 ).

Table 1. The prevalence of physician-diagnosed asthma and other symptoms in the study group

\begin{tabular}{|c|c|c|c|}
\hline \multicolumn{2}{|l|}{ Variables } & n (total 511) & $\%$ \\
\hline \multicolumn{2}{|l|}{ Physician-diagnosed asthma } & 58 & 11.4 \\
\hline \multicolumn{2}{|l|}{ Lifetime wheeze } & 155 & 30.3 \\
\hline \multicolumn{2}{|l|}{ Wheeze in the past 12 months } & 86 & 16.8 \\
\hline \multirow[t]{3}{*}{ Number of wheezing attacks in the past 12 months (total=86) } & $1-3$ & 62 & 72.1 \\
\hline & $4-12$ & 14 & 16.3 \\
\hline & $>12$ & 10 & 11.6 \\
\hline \multirow[t]{2}{*}{ Sleep disturbances due to wheeze; nights/weel (total $=43$ ) } & $\leq 1$ & 22 & 51.2 \\
\hline & $>1$ & 21 & 48.8 \\
\hline \multicolumn{2}{|l|}{ Speech-limiting wheeze (total $=86$ ) } & 30 & 34.9 \\
\hline \multicolumn{2}{|l|}{ Exercise-induced wheeze } & 97 & 19 \\
\hline \multicolumn{2}{|l|}{ Night cough in the past 12 months } & 87 & 17 \\
\hline
\end{tabular}

Regarding severity of asthma, overall (72.1\%) of the students reported less than 4 wheezing attacks in the past 12 months. The prevalence of speech-limiting wheeze was $34.9 \%$. Additionally, in the past 12 months (48.8\%) of the students have had sleep disturbance in more than one night per week due to wheezing (Table 1). The morbidity of asthma symptoms was statically significant, more so among the students who reported physician diagnosed asthma 
(Table 2). Regarding asthma control, more than a half of the students diagnosed with asthma had poor control of asthma symptoms according to ACT score, including uncontrolled and partially controlled asthma each in 15 patients $(25.9 \%$ each), and controlled asthma in only 28 patients $(48.2 \%)$.

Table 2. Distribution of prevalence of physician-diagnosed asthma, according to morbidity in sample of 511 male adolescent, age 16-18 in Arar city, 2017-2018 academic years

\begin{tabular}{|l|l|l|l|l|}
\hline Item & \multicolumn{2}{l|}{ Physician-diagnosed asthma, $\mathrm{n}(\%)$} & \multirow{2}{*}{ p-value } \\
\cline { 3 - 5 } & & Yes & No & \\
\hline Wheeze in the past 12 months & $27(46.5)$ & $59(13.1)$ & $<0.001$ \\
\hline Number of wheezing attacks in the past 12 months & $1-3$ & $15(25.8)$ & $47(10.3)$ & $<0.001$ \\
& $4-12$ & $9(15.6)$ & $5(1.2)$ & \\
\cline { 2 - 4 } & $>12$ & $3(5.1)$ & $7(1.5)$ & \\
\hline Sleep disturbances due to wheeze & $18(31.1)$ & $25(5.5)$ & $<0.001$ \\
\hline Speech-limiting wheeze & $13(22.4)$ & $17(3.8)$ & $<0.001$ \\
\hline
\end{tabular}

\section{Discussion}

The present study estimated asthma prevalence in boys at adolescent age and assessed the level of their asthma control in Arar city (Capital of the Northern Borders Region in Saudi Arabia). The prevalence of physiciandiagnosed asthma was $11.4 \%$. The prevalence of asthma symptoms was $30.3 \%$ for lifetime wheeze, $16.8 \%$ for current (in past 12 months) wheezing and 19\% for exercise induced wheezing throughout the past 12 months. Among students whom reported physician-diagnosed asthma, 51.8\% of them have a poor control of asthma symptoms according to the asthma control test. According to the Saudi Initiative for Asthma, the available data are inadequate regarding asthma prevalence in adolescents aged 16-18 years old (1). In Saudi Arabia, asthma has an increasing pattern (9). Several studies were performed to evaluate asthma prevalence by utilizing the ISAAC survey in Saudi Arabia and other gulf countries (11, 12, 28-31). Asthma in the Northern Borders Region was within the same rate compared to other regions in KSA, and the prevalence was $6.45 \%$ according to the self-administered national household survey in 2013 (13). Now, it is alarming to know that the prevalence of asthma has markedly increased in the Northern Borders Region of Saudi Arabia from 6.45\% to $11.4 \%$ over only a few years. The reason behind this rise is unknown but, it is probably because of a newly-built industrial city in the Northern Borders Region which operates on the process of Phosphate Extraction. A previous study in Saudi Arabia was conducted to compare prevalence of physician-diagnosed asthma in the industrial city of Yanbu to two nonindustrial villages (32). The study revealed high rates in industrial areas $13.9 \%$ compared to nonindustrial areas $8 \%$ (32). This study found that the prevalence of physician-diagnosed asthma was $11.4 \%$ and it is within the national range of $8 \%$ to $23 \%$ that was reported by Al Frayh et al. (9). The recent studies conducted in Saudi Arabia reported that the prevalence of physician-diagnosed asthma in Riyadh city was between 4.5\% and 19.6\% and in Najran city was 27.5\% (10-12). Also, in other regions of Saudi Arabia such as, Madinah city, Abha city and Taif area, the prevalence of asthma was $23.6 \%, 9 \%$ and $13.1 \%$, respectively (14-16). These finding indicate a clear variation in the prevalence rate between the different regions of Saudi Arabia, which might be related to lifestyle, hereditary, and different environmental factors. Furthermore, there is adequate evidence which suggests that the variability in the external allergens may demonstrate the diversity of asthma prevalence between the regions among the same kingdom (27). In addition, the prevalence of physician-diagnosed asthma in other gulf countries was reported as: $10.6 \%$ in Oman, $13 \%$ in the United Arab Emirates, 15.6\% in Kuwait and 19.8\% in Qatar (28-31). Our study estimated high rates of asthma symptoms. The rate of lifetime wheezing at 30.3\% was higher than the reported rate from other regions in the Kingdom such as, Riyadh city which was $25.3 \%$, Najran city (20.3\%) and Jeddah city (21.2\%) (11, 12, 33). Additionally, the prevalence of wheeze in the past 12 months in this study was $16.8 \%$, which is higher than other reported rates such as, Madinah city (10.2\%), Abha city (8\%) and Taif area (3.4\%) (14-16). These high rates of lifetime wheezing and current wheeze may be attributed to the high index of respiratory diseases that is associated with wheezing in the Northern Borders Region of Saudi Arabia. The present study revealed that the prevalence of current (past 12 months) wheeze was $16.8 \%$ in the study population, and $72.1 \%$ of them reported less than 4 wheezing attacks in the last 12 months. Additionally, the prevalence of exercise-induced wheezing and night coughing during the past 12 months was $19 \%$ and $17 \%$ respectively. According to the morbidity of asthma symptoms, the prevalence of speech-limiting wheeze was $34.9 \%$ out of the students whom reported wheezing attacks in the past 12 months. Also, among the students who experienced sleep disturbances, $48.8 \%$ have more than one sleepless night per week because of wheezing. Among students who reported no physician-diagnosed asthma, the prevalence of current (past 12 months) wheeze, speech-limiting wheeze and sleep disturbances were 13.1\%, 
$3.8 \%$ and $5.5 \%$ respectively. These rates of morbidity have a major impact on the quality of life, and it may relate to under-diagnoses of asthma. To determine the level of asthma control, the asthmatic students completed the asthma control test (ACT). Among the physician-diagnosed asthma students (11.4\%), the level of asthma control was $48.2 \%$ and the level of asthma uncontrolled was $25.9 \%$. It is obvious that, more than half of the students who reported physician-diagnosed asthma need to step up their medication according to the guideline of the Saudi Initiative for Asthma 2016 (1). The factors of uncontrolled asthma were not assessed in this study but, many previous studies have looked for reasons behind uncontrolled asthma. Factors such as depression, poor knowledge about asthma, incorrect inhaler used, smoking and diet habits were all associated with poor asthma control (34-38). In the Northern Borders Region of Saudi Arabia, (92.5\%) of the hospitals have no respiratory therapists (39). With respect to other uncontrolled asthma factors, the majority of patients with respiratory diseases in the Northern Borders Region of Saudi Arabia were receiving the services from a non respiratory therapist staff. The health care provided by eligible respiratory therapists, has a critical role in promoted patient outcome (40).

\section{Strength and limitations}

The present research was a descriptive cross-sectional study. This is the first study conducted in the Northern Borders Region of Saudi Arabia to estimate asthma prevalence among adolescent age. Results of this study may act as a baseline for further asthma studies in our region. The study has limitations as it is a self-administered questionnaire. Also, female students were not studied because of systems, cultures and social reasons.

\section{Conclusions}

The prevalence of asthma in the Northern Borders Region of Saudi Arabia was 11.4\%, and 51.8\% of whom were uncontrolled. The rate of asthma and asthma related symptoms is high among 16 to 18 -year-old adolescents and half of the asthmatic students need to step up their medication. Awareness campaigns on asthma are recommended to be conducted by Ministry of Health for adolescents at the schools. Further studies are needed to explore the factors of uncontrolled asthma, and to assess the physicians' understanding and implementation of the SINA guidelines for the diagnosis and management of asthma.

\section{Acknowledgments:}

As the paper was original, the authors would like to thank the members of the health affairs department at the Directorate of Education in the Northern Borders Region, the school directors and the students for their collaboration. Also, we gratefully acknowledge Dr. Hitham Al-Amir (consultant family medicine-NGHA), Dr. Jerman Al-Qahtani (consultant family medicine) and Dr. Ola Al-Qudah (consultant family medicine) for their help in the translation of the ISAAC questionnaire to Arabic language. We highly appreciate Mrs. Rahaf Al-Ruwaili (nutrition specialist) for her help and support throughout the research steps.

\section{Conflict of Interest:}

There is no conflict of interest to be declared.

\section{Authors' contributions:}

All authors contributed to this project and article equally. All authors read and approved the final manuscript.

\section{References:}

1) Al-Moamary MS, Alhaider SA, Idrees MM, Al Ghobain MO, Zeitouni MO, Al-Harbi AS, et al. The Saudi Initiative for Asthma-2016 update: Guidelines for the diagnosis and management of asthma in adults and children. Ann Thorac Med. 2016; 11(1): 3-42. doi: 10.4103/1817-1737.173196. PMID: 26933455, PMCID: PMC4748613.

2) Bitsko MJ, Everhart RS, Rubin BK. The adolescent with asthma. Paediatr Respir Rev. 2014; 15(2): 146-53. doi: 10.1016/j.prrv.2013.07.003. PMID: 23972334.

3) Halwani R, Al-kufeidy R, Muharib BA, Alkhashram FM, Hussain SIB, Alhenaki RS, et al. Impact of Asthma on the Quality of Life of Adolescent Patients from Saudi Arabia. Lung Dis Treat. 2016; $2(3): 114$. doi: 10.4172/2472-1018.1000114.

4) Lochte L, Nielsen KG, Petersen PE, Platts-Mills TAE. Childhood asthma and physical activity: a systematic review with meta-analysis and Graphic Appraisal Tool for Epidemiology assessment. BMC Pediatr. 2016; 16: 50. doi: 10.1186/s12887-016-0571-4. PMID: 27091126, PMCID: PMC4836150.

5) GBD 2015 Chronic Respiratory Disease Collaborators. Global, regional, and national deaths, prevalence, disability-adjusted life years, and years lived with disability for chronic obstructive pulmonary disease and 
asthma, 1990-2015: a systematic analysis for the Global Burden of Disease Study 2015. The Lancet Respiratory Medicine; 2017.

6) Mallol J, Crane J, von Mutius E, Odhiambo J, Keil U, Stewart A, et al. The International Study of Asthma and Allergies in Childhood (ISAAC) Phase Three: a global synthesis. Allergol Immunopathol (Madr). 2013; 41: 73-85. doi: 10.1016/j.aller.2012.03.001. PMID: 22771150.

7) World Health Organization. WHO |Asthma. Available from: http://www.who.int/mediacentre/factsheets/fs307/en/.

8) Mirzaei M, Karimi M, Beheshti S, Mohammadi M. Prevalence of asthma among Middle Eastern children: A systematic review. Medical Journal of the Islamic Republic of Iran. 2017; 31(1): 9. doi: 10.18869/mjiri.31.9.

9) Al Frayh AR, Shakoor Z, Gad El Rab MO, Hasnain SM. Increased prevalence of asthma in Saudi Arabia. Ann Allergy Asthma Immunol. 2001; 86: 292-6. doi: 10.1016/S1081-1206(10)63301-7.

10) Alanazi RK, Bahadir NI, Alghamdi AA, Omar Mohammed Almutairi OM, Alzayed ZM, Al Amoudi SS, et al. Asthma among Adolescent Secondary-School Girls in Riyadh City, Saudi Arabia. Egyptian Journal of Hospital Medicine. 2018; 70(7): 1159-63. doi: 10.12816/0044543.

11) Al Ghobain MO, Al-Hajjaj MS, Al Moamary MS. Asthma prevalence among 16-to 18-year-old adolescents in Saudi Arabia using the ISAAC questionnaire. BMC Public Health. 2012; 12(1): 239. doi: 10.1186/14712458-12-239. PMID: 22443305, PMCID: PMC3384472.

12) Alqahtani JM. Asthma and other allergic diseases among Saudi schoolchildren in Najran: The need for a comprehensive intervention program. Ann Saudi Med. 2016; 36(6): 379-85. doi: 10.5144/02564947.2016.379. PMID: 27920408.

13) Moradi-Lakeh M, El Bcheraoui C, Daoud F, Tuffaha M, Kravitz H, Al Saeedi M, et al. Prevalence of asthma in Saudi adults: findings from a national household survey, 2013. BMC Pulm Med. 2015; 15: 77. doi: 10.1186/s12890-015-0080-5. PMID: 26216220, PMCID: PMC4517561.

14) Nahhas M, Bhopal R, Anandan C, Elton R, Sheikh A. Prevalence of allergic disorders among primary school-aged children in Madinah, Saudi Arabia: Two-stage cross-sectional survey. PLoS One. 2012; 7 : e36848. doi: 10.1371/journal.pone.0036848. PMID: 22615824, PMCID: PMC3355178.

15) Alshehri MA, Abolfotouh MA, Sadeg A, Al Najjar YM, Asindi AA, Al Harthi AM, et al. Screening for asthma and associated risk factors among urban school boys in Abha city. Saudi Med J. 2000; 21(11): 1048-53. PMID: 11360067.

16) Hamam F, Eldalo A, Albarraq A, Khaleel M, Kaabi Y, Al Ghamdi A, et al. The prevalence of asthma and its related risk factors among the children in Taif area, Kingdom of Saudi Arabia. Saudi J Health Sci. 2015; 4(3): 179-84.

17) Harver HKA, Kotses H. Asthma, Health and Society. New York: Springer; 2010

18) Sennhauser FH, Braun-Fahrlander C, Wildhaber JH. The burden of asthma in children: a European perspective. Paediatr Respir Rev. 2005; 6(1): 2-7. doi: 10.1016/j.prrv.2004.11.001. PMID: 15698807.

19) Institute for Health Metrics and Evaluation (IHME). GBD Compare Data Visualization. Seattle, WA: IHME, University of Washington; 2016. Available from: http://vizhub.healthdata.org/gbd-compare.

20) Memish ZA, Jaber S, Mokdad AH, AlMazroa MA, Murray CJL, Al Rabeeah AA, Saudi Burden of Disease Collaborators Burden of disease, injuries, and risk factors in the Kingdom of Saudi Arabia, 1990-2010. Prev Chronic Dis. 2014; 11.

21) Abdul Salam A, Elsegaey I, Khraif R, Al-Mutairi A. Population distribution and household conditions in Saudi Arabia: reflections from the 2010 Census. Springer Plus. 2014; 3: 530. doi: 10.1186/2193-1801-3530. PMID: 25279321, PMCID: PMC4174546.

22) General Directorate of Education in the Northern Border Region. Available from: http://www.northedu.gov.sa/.

23) Charan J, Biswas T. How to calculate sample size for different study designs in medical research?. Indian journal of psychological medicine. 2013; 35(2): 121. doi: 10.4103/0253-7176.116232. PMID: 24049221, PMCID: PMC3775042.

24) The international study of asthma and allergies in childhood (ISAAC) steering committee. Worldwide variation in prevalence of symptoms of asthma, allergic rhinoconjunctivits, and atopic eczema: ISAAC. Lancet. 1998; 351: 1225-32. doi: 10.1016/S0140-6736(97)07302-9.

25) Jenkins MA, Clarke JR, Carlin JB, Robertson CF, Hopper JL, Dalton MF, et al. Validation of questionnaire and bronchial hyperresponsiveness against respiratory physician assessment in the diagnosis of asthma. Int J Epidemiol. 1996; 25(3): 609-16. doi: 10.1093/ije/25.3.609. PMID: 8671563. 
26) Lababidi H, Hijaoui A, Zarzour M. Validation of the Arabic version of the asthma control test. Annals of thoracic medicine. 2008; 3(2): 44. doi: 10.4103/1817-1737.39635. PMID: 19561904, PMCID: PMC2700459.

27) Al-Frayh AR, El-Rab MOG, Al-Najjar AR, Hasnain SM. A comparative study of immediate skin test reacting to inhalant allergens in asthmatic children of two different regions in Saudi Arabia. Anns Saudi Med. 1992; 12: 468-71. doi: 10.5144/0256-4947.1992.468.

28) Al-Rawas OA, Al-Riyami BM, Al-Maniri AA, Al-Riyami AA. Trends in asthma prevalence and severity in Omani schoolchildren: comparison between ISAAC phases I and III. Respirology. 2008; 13: 670-3. doi: 10.1111/j.1440-1843.2008.01313.x. PMID: 18513242.

29) Al-Maskari F, Bener A, Al-Kaabi A, Al-Suwaidi N, Norman N, Brebner J. Asthma and respiratory symptoms among school children in United Arab Emirates. Allerg Immunol (Paris). 2000; 32(4): 159-63. PMID: 10900696.

30) Owayed A, Behbehani N, Al-Momen J. Changing prevalence of asthma and allergic diseases among Kuwaiti children. An ISAAC Study (Phase III). Med Princ Pract. 2008; 17: 284-289. doi: 10.1159/000129607. PMID: 18523395.

31) Janahi IA, Bener A, Bush A. Prevalence of asthma among Qatari schoolchildren: international study of asthma and allergies in childhood, Qatar. Pediatr Pulmonol. 2006; 41: 80-6. doi: 10.1002/ppul.20331. PMID: 16283628.

32) Al-Shairi A, Al-Dawood K. Schoolboys in urban industrial environments: are they at increased risk of bronchial asthma? East Mediterr Health J. 1999; 5: 657-63. PMID: 11338687.

33) Hijazi N, Abalkhail B, Seaton A: Asthma and respiratory symptoms in urban and rural Saudi Arabia. Eur Respir J. 1998, 12: 41-4. doi: 10.1183/09031936.98.12010041. PMID: 9701412.

34) Merghani TH, Alawad AO. Indicators of Asthma Control in Asthmatic Patients: Are they related to Depression? Open Access Maced J Med Sci. 2017; 5(5): 673-6. doi: 10.3889/oamjms.2017.091. PMID: 28932312, PMCID: PMC5591601.

35) Al-Muhsen S, Horanieh N, Dulgom S, Aseri ZA, Vazquez-Tello A, Halwani R, et al. Poor asthma education and medication compliance are associated with increased emergency department visits by asthmatic children. Ann Thorac Med. 2015; 10(2): 123-31. doi: 10.4103/1817-1737.150735. PMID: 25829964, PMCID: PMC4375741.

36) Al-Zahrani JM, Ahmad A, Al-Harbi A, Khan AM, Al-Bader B, Baharoon S, et al. Factors associated with poor asthma control in the outpatient clinic setting. Ann Thorac Med. 2015; 10(2): 100-4. doi: 10.4103/1817-1737.152450. PMID: 25829960, PMCID: PMC4375737.

37) Al-Jahdali HH, Al-Hajjaj MS, Alanezi MO, Zeitoni MO, Al-Tasan TH. Asthma control assessment using asthma control test among patients attending 5 tertiary care hospitals in Saudi Arabia. Saudi Med J. 2008; 29: 714-7. PMID: 18454220.

38) Hijazi N, Abalkhail B, Seaton A. Diet and childhood asthma in a society in transition: a study in urban and rural Saudi Arabia. Thorax. 2000; 55(9): 775-9. doi: 10.1136/thorax.55.9.775. PMID: 10950897, PMCID: PMC1745853.

39) Alotaibi G. Status of respiratory care profession in Saudi Arabia: A national survey. Annals of Thoracic Medicine. 2015; 10(1): 55-60. doi: 10.4103/1817-1737.146878. PMID: 25593609, PMCID: PMC4286847.

40) Stoller JK. 2000 Donald F. Egan Scientific Lecture. Are respiratory therapists effective? Assessing the evidence. Respir Care. 2001; 46: 56-66. PMID: 11175240. 